\title{
Influencing Factors of Channel Collaboration in Multi-channel Supply Chain: A Contextual Ambidexterity-Based Analysis from the Perspective of Traditional Retailer
}

\author{
Min Wang ${ }^{1,2}$, Xumei Zhang ${ }^{1,2^{*}}$, Mingyue Fan ${ }^{1,2}$, Mei Hao ${ }^{1,2}$ \\ ${ }^{1}$ School of Economics \& Business Administration, Chongqing University, Chongqing 400044, China \\ ${ }^{2}$ Chongqing Key Laboratory of Logistics at Chongqing University, Chongqing 400044, China
}

Corresponding Author Email: zhangxumei@cqu.edu.cn

https://doi.org/10.18280/jesa.520612

Received: 8 June 2019

Accepted: 10 September 2019

\section{Keywords:}

multi-channel supply chain (SC), channel collaboration, contextual ambidexterity, traditional sales channel, direct sales channel

\begin{abstract}
In multi-channel supply chain (SC), the traditional retailer can get service returns through collaboration with the direct sales channel of the manufacturer. It is very meaningful to identify the influencing factors of the channel collaboration and disclose their impacts. This paper firstly considers the cross-channel behavior of consumers, which stimulates the traditional retailer to improve its service level, and in turn exerts a spillover effect on the demand for the direct sales channel. Hence, a Stackelberg game model was set up between the manufacturer and the retailer to explore the spillover effect on pricing and service decisions. The results show that the spillover effect promotes the retailer's service level, lowers the manufacturer's wholesale price, and increases the profits of both sides. Next, an empirical model was built based on contextual ambidexterity, which covers multiple variables and mediators. The model was applied to examine the correlations of channel collaboration and collaboration performance with cross-channel behavior and other key factors. The empirical analysis was based on the data collected from 221 traditional retailers in multi-channel SCs across China. Through the analysis, it is confirmed that the collaboration performance is greatly promoted by the cross-channel behavior (on the level of environmental adaptation), as well as channel complementation and trust (on the level of task alignment), and the promoting effects are mediated by the three dimensions of channel collaboration, namely, special investment, information sharing and joint action. The research findings provide new insights into the channel collaboration between the traditional retailer and the manufacturer in multi-channel $\mathrm{SC}$, and offer new empirical evidence to studies on contextual ambidexterity and channel behavior.
\end{abstract}

\section{INTRODUCTION}

Before the Internet era, the retailer is the core of the traditional sales channel. In recent years, the development of e-commerce has given rise to the direct sales channel, through which the manufacturer directly sells products to consumers. Considering the varied preferences of sales channels among consumers, many manufacturers, such as Haier and HP, have integrated the traditional and direct sales channels in the downstream of the supply chain (SC), creating a multi-channel $\mathrm{SC}$ that adapts to the consumer demand [1].

The collaboration between the two sales channels have attracted much attention from the academia. However, the existing studies mainly tackle the collaboration strategy of the manufacturer in the multi-channel SC, e.g. the coordination of pricing, inventory, advertising and promotion [2-4]. There is little report on the retailer behavior in the multi-channel SC.

Based on theories of SC management and channel behavior, this paper assumes that, in channel collaboration, the crosschannel behavior of consumers and the service of traditional sales channel have a spillover effect on the demand for the direct sales channel.

Under this assumption, a Stackelberg game model was set up between the manufacturer and the retailer to identify the optimal pricing, service level and collaboration performance. From the perspective of contextual ambidexterity, the influencing factors of channel collaboration were verified through empirical analysis.

\section{LITERATURE REVIEW}

\subsection{Multi-channel collaboration}

The collaboration between traditional and direct sales channels has been extensively explored through theoretical, quantitative and empirical analyses. Some scholars probed deep into the motivations, opportunities and challenges of multi-channel collaboration, and developed relevant models and strategies. Some scholars studied the channel coordination from the perspective of the core manufacturer, which covers revenue distribution, inventory coordination, information sharing, cooperative advertising and joint promotion [2-5]. Some other scholars focused on the channel collaboration of large independent retailers.

For example, Oh et al. [6] identified the correlations between information technology (IT), human resources and collaboration performance. Schramm et al. [7] and Gallino and Moreno [8] disclosed the influence of channel collaboration on consumer satisfaction, loyalty and the collaboration performance of SC members. 


\subsection{Dimensions of channel collaboration}

The channel collaboration aims to satisfy the consumer demand for multi-channel shopping, and simplify the links between different shopping stages [9]. The information sharing system makes it possible to provide multi-channel services to consumers through product pricing, inventory collaboration and joint promotion in multiple channels. The typical services include location search, out-of-stock product inquiry, online ordering and offline pickup, online purchase and offline return, cross-channel couponing, etc. [9, 10].

In the light of the SC management theory, the channel collaboration of multi-channel SC can be regarded as a collaboration relationship, which depends on the collaboration of SC members. Ramanathan [11] and Jap [12] classified channel collaboration into three dimensions, namely, special investment, information sharing and joint action. Among them, special investment, including the money, equipment, manpower and process invested by the retailer and the manufacturer, promotes the willingness, relationship and efficiency of collaboration, while suppressing opportunism; information sharing refers to the exchange between the traditional and direct sales channels in terms of sales, inventory, order and demand; joint action stands for the concerted efforts between the retailer and the manufacturer to pursue the common goal, share the inventory, set the product price, promote the products, and distribute the income. Despite the depth and complexity of collaboration in multi-channel context, the collaboration behaviors can also be categorized into the above three dimensions.

\subsection{Influencing factors of channel collaboration from the angle of contextual ambidexterity}

The above review shows that the retailer should adapt its traditional sales channel to the multi-channel environment. Besides the cross-channel behavior of consumers, the contextual ambidexterity should be considered to optimize the adaptation process. Proposed by Gibson and Birkinshaw, the contextual ambidexterity theory tackles the capability or process of an enterprise to adapt to the external dynamic environment and align for a common goal [13, 14]. Birkinshaw and Gupta [15] suggested that an effective way to achieve ambidexterity is to expand new channels. Therefore, the influencing factors of channel collaboration may come from two aspects: environmental adaptation and task alignment.

In response to the call for an in-depth research into contextual ambidexterity, this paper attempted to explain the channel collaboration of multi-channel SC from the perspective of the traditional retailer, considering both Stackelberg game and contextual ambidexterity [16].

\section{STACKELBERG GAME MODEL}

\subsection{Problem description}

As shown in Figure 1, our problem considers an SC involving an independent traditional retailer $(r)$ and a manufacturer $(m)$. Through the traditional sales channel, the manufacturer sells products to the retailer at the wholesale price $w$, and then the retailer sells them to consumers at the retail price. Through the direct sales channel, the manufacturer sells products directly to consumers at the direct sales price. To avoid price competition and alleviate channel conflict, it is assumed that the retail price equals the direct sales price, both of which are denoted as $p$. To encourage offline purchase, the retailer provides services at the level $s_{r}$ to consumers.

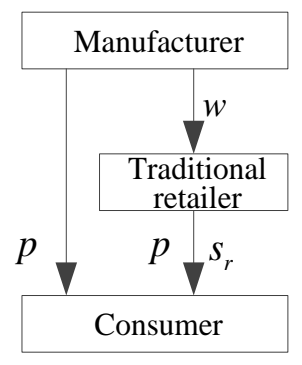

Figure 1. The SC structure under channel collaboration

After receiving the retailer's service, some consumers choose to purchase through the direct sales channel. This phenomenon is defined as the cross-channel behavior. Thus, the retailer's service is considered to have a spillover effect $b_{m}$ on the demand for the direct sales channel. Then, the demands for the direct sales channel and the traditional sales channel can be respectively calculated by:

$$
\begin{aligned}
& d_{\mathrm{m}}=k_{\mathrm{m}}-p+b_{\mathrm{m}} s_{\mathrm{r}} \\
& d_{\mathrm{r}}=1-k_{m}-p+s_{r}
\end{aligned}
$$

where, $k_{m}$ and $1-k_{m}(0<k<1)$ are the market shares of the online and traditional sales channels, respectively.

Considering the cost of the retailer's service, it is assumed that the service cost is $C\left(s_{\mathrm{r}}\right)=\frac{1}{2} s_{\mathrm{r}}^{2}$, and satisfies $\partial C\left(s_{r}\right) / \partial s_{r}>0$ and $\partial^{2} C\left(s_{\mathrm{r}}\right) / \partial s_{\mathrm{r}}^{2}>0$. This assumption is widely accepted in previous literature [2]. Then, the profits of the manufacturer and the retailer can be respectively expressed as:

$$
\begin{gathered}
\pi_{\mathrm{m}}=p d_{\mathrm{m}}+w d_{\mathrm{r}} \\
\pi_{r}=(p-w) d_{\mathrm{r}}-\frac{1}{2} s_{r}^{2}
\end{gathered}
$$

Table 1. The symbols of the Stackelberg game model

\begin{tabular}{cc}
\hline Symbol & Description \\
\hline$w$ & The wholesale price set by the manufacturer \\
$p$ & The retail price set by the retailer \\
$s_{r}$ & The service level of the retailer \\
$k_{m}$ & The market share of the direct sales channel \\
$b_{m}$ & The spillover effect of the retailer's service on the \\
\hline
\end{tabular}

On this basis, a Stackelberg game model was established between the manufacture and the retailer, with the latter providing services to satisfy the empirical demand of crosschannel consumers. Being the leader of the game, the manufacturer first sets a wholesale price $w$. Then, the retailer, the follower, sets the service level $s_{r}$ and the retail price $p$. Through the game, the consumer demand is fulfilled, and both the manufacturer and the retailer make profits. The relevant symbols are listed in Table 1 above. 


\subsection{Model solution and analysis}

Under equilibrium conditions, the optimal wholesale price, service level and retail price can be respectively described as:

$$
\begin{gathered}
p=1-k \\
s_{\mathrm{r}}=1-k_{m}-w \\
w=\frac{1}{2} b_{m} k_{m}-\frac{1}{2} b_{m}-\frac{1}{2} k_{m}+\frac{1}{2}
\end{gathered}
$$

Solving the second-order derivative of retailer's profit function about $s_{r}$ and $p$, the Hessian matrix can be established as:

$$
\begin{aligned}
H\left(s_{\mathrm{r}}, p\right) & =\left(\begin{array}{ll}
\partial^{2} \pi_{r} / \partial s_{\mathrm{r}}^{2} & \partial^{2} \pi_{r} / \partial s_{\mathrm{r}} \partial p \\
\partial^{2} \pi_{r} / \partial s_{\mathrm{r}} \partial p & \partial^{2} \pi_{r} / \partial p^{2}
\end{array}\right) \\
& =\left(\begin{array}{cc}
-1 & 1 \\
1 & -2
\end{array}\right)
\end{aligned}
$$

Since the Hessian matrix is negative, $\pi_{r}$ is a joint concave function of $s_{r}$ and $p$. To maximize the retailer's profit, the retailer's optimal decisions on the retail price and service level must satisfy $\partial \pi_{r} / \partial s_{r}=0$ and $\partial \pi_{r} / \partial p=0$. Hence, the equilibrium results can be derived as:

$$
\begin{gathered}
\frac{\partial \pi_{r}}{\partial s_{\mathrm{r}}}=p-w-s_{\mathrm{r}} \\
\frac{\partial \pi_{r}}{\partial p}=1-k_{\mathrm{m}}-2 p+s_{\mathrm{r}}+w
\end{gathered}
$$

The optimal solutions of $s_{r}$ and $p$ can be obtained by solving $\partial \pi_{r} / \partial s_{r}=0$ and $\partial \pi_{r} / \partial p=0$. Substituting the solutions to formula (3), the manufacturer's profit can be obtained as:

$$
\begin{aligned}
& \pi_{\mathrm{m}}=w b_{m} k_{m}+b_{m} k_{m}{ }^{2}-w^{2}-w b_{m}-w k_{m}- \\
& 2 b_{m} k_{m}-2 k_{m}^{2}+w+b_{m}+3 k_{m}-1
\end{aligned}
$$

The second-order derivative of $\pi_{m}$ about $w$ can be solved as:

$$
\frac{\partial \pi_{\mathrm{m}}^{2}}{\partial w^{2}}=-2<0
$$

Then, the optimal solution of $w$ can be obtained by solving $\partial \pi_{m} / \partial w=0$.

Through the above analysis, the following propositions were put forward:

Proposition 1. $\frac{\partial s_{\mathrm{r}}}{\partial b_{\mathrm{m}}}>0$.

Proof. Solving the partial derivative solutions, we have:

$$
\begin{gathered}
s_{\mathrm{r}}=-\frac{1}{2}\left(k_{m}-1\right)\left(b_{m}+1\right) \\
\frac{\partial s_{\mathrm{r}}}{\partial b_{\mathrm{m}}}=-\frac{1}{2} k_{m}+\frac{1}{2}>0
\end{gathered}
$$

Q.E.D.

Proposition 1 reveals that, under the spillover effect of retailer's service, the retailer tends to improve rather than reduce the service level. When consumers take a free ride by committing the cross-channel behavior, the retailer will try to attract consumer demand by improving the service level. The spillover effect initiates the coordinates between the retailer and the manufacturer. As the cause of the spillover effect, the cross-channel behavior of consumers is the key driver of channel collaboration.

Proposition 2. $\frac{\partial p}{\partial b_{\mathrm{m}}}=0$, and $\frac{\partial w}{\partial b_{\mathrm{m}}}<0$.

Proof. Formula (5) shows that $\frac{\partial p}{\partial b_{\mathrm{m}}}=0$;

Solving the partial derivative of $w$ about $b_{m}$, we have $\frac{\partial w}{\partial b_{\mathrm{m}}}=\frac{1}{2} k_{m}-\frac{1}{2}<0$.

Q.E.D.

Proposition 2 shows that the spillover effect influences the wholesale price. Meanwhile, the retail price has nothing to do with the spillover effect. It is mainly affected by the market share of the direct sales channel. If the demand for the direct sales channel decreases, the retailer will set a higher retail price to make more profits. If the demand for the direct sales channel increases, the retailer will set a lower retail price to attract more consumers. Moreover, the demand of crosschannel consumers can be fulfilled by the spillover effect, pushing up the demand for the direct sales channel. The manufacturer will lower the wholesale price and give more profit space to the retailer, aiming to compensate for the retailer's loss and encourage the retailer to improve the service level (which in turn increases the demand for the direct sales channel).

Proposition 3. $\frac{\partial \pi_{r}}{\partial b_{\mathrm{m}}}>0$ and $\frac{\partial \pi_{m}}{\partial b_{\mathrm{m}}}>0$.

Proof. The partial derivative solutions can be obtained as:

$$
\begin{gathered}
\pi_{r}=\frac{1}{8}\left(k_{m}-1\right)^{2}\left(b_{m}+1\right)^{2} \\
\frac{\partial \pi_{r}}{\partial b_{\mathrm{m}}}=\frac{1}{4}\left(k_{m}-1\right)^{2}\left(b_{m}+1\right)>0
\end{gathered}
$$

$$
\begin{gathered}
\pi_{m}=\frac{1}{4}\left(k_{m}-1\right)\left(b_{m}{ }^{2} k_{m}-b_{m}{ }^{2}+2 b_{m} k_{m}-2 b_{m}-7 k_{m}+3\right) \\
\frac{\partial \pi_{m}}{\partial b_{\mathrm{m}}}=\frac{1}{4}\left(k_{m}-1\right)\left(2 b_{m} k_{m}-2 b_{m}+2 k_{m}-2\right)>0
\end{gathered}
$$

Q.E.D.

Proposition 3 indicates that the spillover effect increases the profits of both the retailer and the manufacturer. By improving the service level, the retailer attracts more offline consumers, and thus makes more profits. The improved service level will push up the demand for the direct sales channel. Then, the manufacturer will lower the wholesale price to encourage the retailer to further improve the service level. In this way, the retailer will receive service compensation and more profits. The manufacturer also makes more profits, thanks to the growing demand for the direct sales channel, driven by the rising service level. To sum up, when consumers commit cross-channel behavior, both the retailer and the manufacturer 


\section{THEORETICAL ANALYSIS}

Under the framework of contextual ambidexterity, this section mainly identifies the influencing factors (e.g. crosschannel behavior) of channel collaboration of multi-channel $\mathrm{SC}$ and theoretically analyze their specific impacts.

Based on contextual ambidexterity theory, Gibson and Birkinshaw [14] highlighted the importance of support and trust to the success of an enterprise. Some studies have shown that external environment and market orientation bear on the relationship between organizational ambidexterity and performance. Therefore, this paper identifies the influencing factors and hypothesizes their impacts from the environmental adaptation and task alignment level $[17,18]$.

\subsection{Influencing factors on the level of environmental adaptation}

(1) Cross-channel behavior

With the boom of e-commerce, consumers are accustomed to shopping in multiple channels and maximizing the utility of each channel. Facing the market change, the traditional retailer starts to pay attention to the influence of channel selection by consumers [19]. To attract consumers, the retailer needs to optimize the service process, deliver more valuable multichannel services, and cooperate with the direct sales channel to turn potential consumer value into performance. Therefore, the following hypotheses were put forward:

H1a. Cross-channel behavior has a positive effect on collaboration performance.

H1b. Cross-channel behavior has a positive effect on special investment, which in turn enhances collaboration performance.

H1c. Cross-channel behavior has a positive effect on information sharing, which in turn enhances collaboration performance.

H1d. Cross-channel behavior has a positive effect on joint action, which in turn enhances collaboration performance.

(2) Competition pressure

Valos et al. [20] proved that the enterprises actively operating multiple channels have a competitive edge over those clinging to only one channel or failing to collaborate effectively. More than $24 \%$ sales volume is lost because multichannel consumers turn to the traditional sales channel of competitors, after looking up product information on the website or direct sales channel of an enterprise [21]. The traditional retailer can attract consumers from its competitors by improving its service. Therefore, the following hypotheses were put forward:

H2a. Competition pressure has a positive effect on collaboration performance.

H2b. Competition pressure has a positive effect on special investment, which in turn enhances collaboration performance.

H2c. Competition pressure has a positive effect on information sharing, which in turn enhances collaboration performance.

H2d. Competition pressure has a positive effect on joint action, which in turn enhances collaboration performance.

\section{(1) Channel complementation}

Under the framework of the resource-based view (RBV), channel complementation refers to the joint pursuit among SC members for the synergy effect between channels by setting up the common goal, optimizing functions and allocating resources, giving full play to their unique and heterogeneous resource [22]. With multiple channels, the enterprises can sell more products, interact more with consumers, create varied sales opportunities and approach market success [23]. Therefore, the following hypotheses were put forward:

H3a. Channel complementation has a positive effect on collaboration performance.

H3b. Channel complementation has a positive effect on special investment, which in turn enhances collaboration performance.

H3c. Channel complementation has a positive effect on information sharing, which in turn enhances collaboration performance.

H3d. Channel complementation has a positive effect on joint action, which in turn enhances collaboration performance.

(2) Manufacturer's channel power

Channel power is the ability of an SC member to achieve its goal by influencing and controlling the market decisions of other members on the other levels of the same SC. The manufacturer boasts a great channel power, in that it could stimulate the retailer through contract and relationship management, and provide collaboration supports. If the manufacturer makes proper use of its power, the channel collaboration will have fewer problems and achieve better results, and the retailer will follow its market decisions and implement special investment, information sharing and joint action. Therefore, the following hypotheses were put forward:

H4a. Manufacturer's channel power has a positive effect on collaboration performance.

H4b. Manufacturer's channel power has a positive effect on special investment, which in turn enhances collaboration performance.

H4c. Manufacturer's channel power has a positive effect on information sharing, which in turn enhances collaboration performance.

H4d. Manufacturer's channel power has a positive effect on joint action, which in turn enhances collaboration performance.

(3) Trust

Trust means an SC member has faith in the technical and commercial competence of the other members, and believes that the latter will act in line with their common interests, despite the environmental uncertainties [24]. The trust mainly depends on honesty, benevolence and talent [25]. In the multichannel SC, trust is the foundation of channel collaboration. With mutual trust, the SC members will enhance relationship, share information and obtain resources from each other. Therefore, the following hypotheses were put forward:

H5a. Trust has a positive effect on collaboration performance.

H5b. Trust has a positive effect on special investment, which in turn enhances collaboration performance.

H5c. Trust has a positive effect on information sharing, which in turn enhances collaboration performance.

H5d. Trust has a positive effect on joint action, which in turn enhances collaboration performance. 


\subsection{Collaboration behavior and performance}

To adapt to the dynamic environment and achieve task alignment, the traditional retailer must pursue collaboration in all three dimensions: special investment, information sharing and joint action. Therefore, the following hypotheses were put forward:

H6. Special investment has a positive effect on collaboration performance.

H7. Information sharing has a positive effect on collaboration performance.

H8. Joint action has a positive effect on collaboration performance.

Through the above discussion, the influencing factors of collaboration performance were modelled (Figure 2), according to the input-output framework of collaboration alliance research. In the following section, the model is adopted to test the above hypotheses, based on the questionnaire data of retailers in multi-channel SCs.

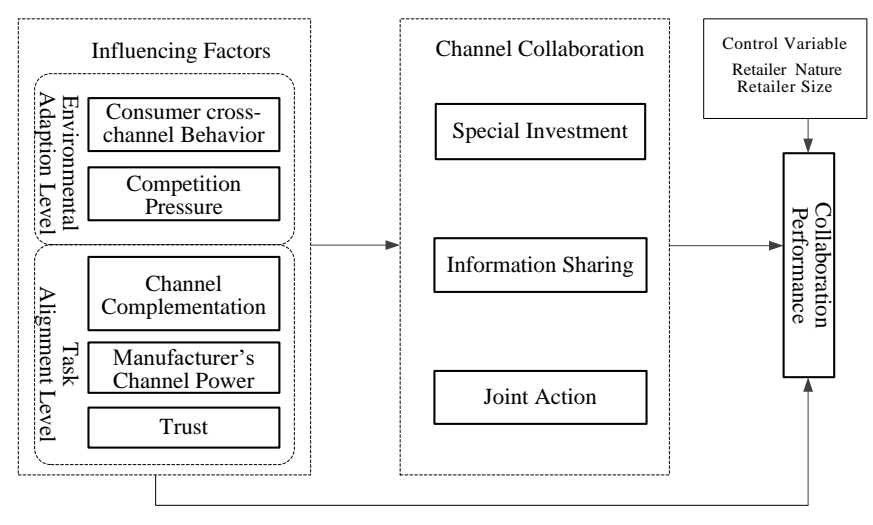

Figure 2. The influencing factors of collaboration performance

\section{EMPIRICAL ANALYSIS}

\subsection{Methodology}

The empirical method was adapted from the previous studies. A questionnaire was prepared in consultation with scholars and experts in the field of multi-channel SC. A pretest was carried out among ten retailing experts. According to the pretest results, the items in the questionnaire were modified to be more realistic. During the questionnaire survey, each item was rated against a 5-point scale, with 1 being strongly disagree and 5 being strongly agree. Based on the survey data, the retailer nature and retailer size were taken as control variables.

Based on previous studies like van Baal and Dach [26], four items were selected to measure the cross-channel behavior, such as "the consumers frequently take free rides by committing cross-channel behavior".

Drawing on Ramdani et al. [27], competition pressure was measured with three items, such as "the direct competitors in the industry began to integrate the traditional sales channel with the direct sales channel".

Inspired by Kollmann and Hasel [5], channel complementation was measured with four items, such as "the direct sales channel provides a cost-effective way to advertise the traditional sales channel".

Following Payan et al. [28], the manufacturer's channel power was measured with four items, such as "we are dependent on the manufacturer".

According to Mayer et al. [25], the three dimensions of trust, namely, honesty, benevolence and talent, were respectively measured with four items.

In the light of Min et al. [29], the channel collaboration was divided into three dimensions: special investment, information sharing and joint action.

In view of Jap [12], the collaboration performance was measured with six items borrowed from inter-organization performance, including three objective items and three subjective items

\subsection{Data samples}

Our questionnaire survey targets the traditional retailers in 14 provincial-level administrative regions across China: Beijing, Shanghai, Chongqing, Guangdong, Zhejiang, Jiangsu, Sichuan, Henan, Shanxi, Shandong, Shaanxi, Hubei, Yunnan and Fujian. A total of 300 questionnaires were issued, and 263 were returned. 221 questionnaires are valid, putting the response rate at $73.6 \%$. The respondents are mainly salesmen or sales managers in the retail industry. $86.8 \%$ of them have worked in this industry for over 5 years; $84.4 \%$ of them have a college degree or above. The profiles of the respondents are illustrated in Table 2.

Table 2. The profiles of the respondents

\begin{tabular}{|c|c|c|c|c|c|c|c|c|c|c|}
\hline & Dataset $(\mathrm{N}=221)$ & $\mathrm{N}$ & $\mathrm{P} \%$ & & Dataset $(\mathrm{N}=221)$ & $\mathrm{N}$ & $\mathrm{P} \%$ & Dataset $(\mathrm{N}=221)$ & $\mathrm{N}$ & $\mathrm{P} \%$ \\
\hline \multirow{3}{*}{$\begin{array}{l}\text { Retailer } \\
\text { nature }\end{array}$} & Private & 106 & 48.4 & \multirow{6}{*}{ Products } & Apparel and accessories & 57 & 26.2 & Jewelry and watches & 6 & 3.2 \\
\hline & $\begin{array}{l}\text { State-owned and } \\
\text { state holding }\end{array}$ & 88 & 39.7 & & Mobile digital equipment & 40 & 18.6 & $\begin{array}{l}\text { Medicines and health } \\
\text { products }\end{array}$ & 6 & 3.2 \\
\hline & $\begin{array}{l}\text { Foreign-funded and } \\
\text { joint venture }\end{array}$ & 27 & 12.2 & & Household appliances & 27 & 12.7 & $\begin{array}{l}\text { Books and } \\
\text { audiovisuals }\end{array}$ & 5 & 2.3 \\
\hline \multirow{3}{*}{$\begin{array}{l}\text { Retailer } \\
\text { size }\end{array}$} & $<50$ employees & 34 & 15.4 & & Daily necessities & 27 & 12.7 & \multirow{3}{*}{$\begin{array}{l}\text { Vehicle supplies } \\
\text { Hair and beauty } \\
\text { products }\end{array}$} & 3 & 1.4 \\
\hline & 50-100 employees & 66 & 29.9 & & Food and beverage & 18 & 8.6 & & 4 & 1.8 \\
\hline & 100-500 employees & $\begin{array}{l}56 \\
65\end{array}$ & 25.3 & & House furnishing materials & 11 & 5.4 & & & \\
\hline
\end{tabular}

\subsection{Non-response bias and common method variance (CMV)}

The final samples were split into two parts based on the time of response. The early and late responses were compared in physical assets, and number of employees. No significant difference was found through the t-tests, indicating that nonresponse bias was not a major concern. 
To reduce the CMV, the questionnaires were issued across a wide range to 14 provincial-level administrative regions. According to the Harman's single factor test, the load of the first principal component factor was below the $50 \%$ threshold $(30.560 \%)$. Hence, the CMV does not have a significant impact on the survey results.

\subsection{Reliability and validity}

The Cronbach's alpha of all variables reached the acceptable level of 0.600 , indicating that the constructs are reliable.
Following Bagozzi and Yi [30], the combined reliability (CR) of all variables was greater than 0.700 , a sign of good internal consistency. The factor analysis shows that the factor load of each variable item was greater than 0.573 , an evidence of good convergence validity.

Suggested by Fornell and Larcker [31], the minimum average variance extracted (AVE) value of each variable was 0.496 , and the rest were above 0.500 . Table 3 shows that the AVE of each variable was greater than the square of the correlation coefficients of all variables. This means the variables in our research enjoy good discriminant validity.

Table 3. The mean, standard deviation and Pearson correlation coefficient of variables

\begin{tabular}{|c|c|c|c|c|c|c|c|c|c|c|c|}
\hline Factor & Mean & Standard deviation & $\mathrm{CB}$ & CPE & $\mathrm{CC}$ & MP & TR & SI & IS & JA & $\mathrm{CP}$ \\
\hline $\mathrm{CB}$ & 3.920 & 0.678 & 0.763 & & & & & & & & \\
\hline CPE & 3.697 & 0.734 & $0.534 * *$ & 0.799 & & & & & & & \\
\hline $\mathrm{CC}$ & 3.723 & 0.744 & $0.452 *$ & $0.424 *$ & 0.708 & & & & & & \\
\hline MP & 3.057 & 0.877 & $0.163 * *$ & 0.120 & 0.074 & 0.839 & & & & & \\
\hline TR & 3.287 & 0.557 & $0.408 * *$ & $0.283 * *$ & $0.360 * *$ & 0.123 & 0.676 & & & & \\
\hline SI & 3.335 & 0.722 & $0.451 * *$ & $0.401 * *$ & $0.342 * *$ & 0.113 & $0.504 * *$ & 0.816 & & & \\
\hline IS & 3.500 & 0.747 & $0.420 * *$ & $0.218^{* *}$ & $0.301 * *$ & 0.110 & $0.523 * *$ & $0.523 * *$ & 0.787 & & \\
\hline JA & 3.294 & 0.779 & $0.360 * *$ & $0.218 * *$ & $0.156^{*}$ & 0.052 & $0.561 * *$ & $0.447 * *$ & $0.569 * *$ & 0.763 & \\
\hline $\mathrm{CP}$ & 3.446 & 0.675 & $0.429 * *$ & $0.282^{* *}$ & $0.351 * *$ & 0.058 & $0.462 * *$ & $0.537 * *$ & $0.491 * *$ & $0.480 * *$ & 0.748 \\
\hline
\end{tabular}

Note: $\dagger$ means $\mathrm{P}<0.100,{ }^{*}$ means $\mathrm{P}<0.050,{ }^{* *}$ means $\mathrm{P}<0.010$, and *** means $\mathrm{P}<0.001$; CB, CPE, CC, MP, TR, SI, IS, JA and CP refer to cross-channel behavior, competition pressure, channel complementation, manufacturer's channel power, trust, special investment, information sharing, joint action, and collaboration performance, respectively.

\subsection{Results analysis}

The influences of independent variables and mediator variables on the dependent variable were tested by multiple regression method. As shown in Table 4, Models 1 and 2 reflect the influence of 5 factors on dependent variables, respectively. The results of the two models show that $\mathrm{CB}, \mathrm{CC}$ and TR have significant effects on the dependent variable, while the regression coefficients of CPE and MP were not significant. Models 3-5 test the influence of CB, CC and TR on SI, IS and JA, respectively. The regression equations are: $S I=a_{11} C B+a_{21} C O+a_{31} T R+e_{S I} ; S=a_{12} C B+a_{22} C O+a_{32} T R+$ $e_{I S} ; J A=a_{13} C B+a_{23} C O+a_{33} T R+e_{J A}$. Model 6 is the complete model that all variables enter the regression equation: $C P=$ $c_{1}{ }^{\prime} C B+c_{2}{ }^{\prime} C O+c_{3}{ }^{\prime} T R+b_{1} S I+b_{2} I S+b_{3} J A+e_{C P}$.

Table 4. The results of multiple regression

\begin{tabular}{|c|c|c|c|c|c|c|}
\hline & Model 1 & Model 2 & Model 3 & Model 4 & Model 5 & Model 6 \\
\hline & \multicolumn{2}{|c|}{$\mathrm{CP}$} & SI & IS & JA & $\mathrm{CP}$ \\
\hline \multicolumn{7}{|l|}{ Control variable } \\
\hline Retailer nature & -0.042 & -0.039 & 0.009 & -0.077 & $0.101 *$ & $-0.048 *$ \\
\hline Retailer size & $0.050 *$ & $0.052 * *$ & $0.109 * *$ & 0.028 & -0.040 & $0.038^{*}$ \\
\hline \multicolumn{7}{|c|}{ Independent variable } \\
\hline $\mathrm{CB}$ & $0.167 * *$ & $0.189 * * *$ & $0.381 * * *$ & 0.196 & $0.239 *$ & 0.099 \\
\hline $\mathrm{CPE}$ & 0.145 & & & & & \\
\hline $\mathrm{CC}$ & $0.108^{\dagger}$ & $0.119^{*}$ & $0.232 *$ & 0.091 & $-0.261 *$ & $0.111^{*}$ \\
\hline MP & 0.001 & & & & & \\
\hline TR & $0.259 * * *$ & $0.262 * * *$ & $0.361 * * *$ & $0.460 * * *$ & $0.761 * * *$ & 0.083 \\
\hline \multicolumn{7}{|l|}{ Mediator variable } \\
\hline SI & & & & & & $0.170^{* * *}$ \\
\hline IS & & & & & & $0.112^{* * *}$ \\
\hline JA & & & & & & $0.162 * * *$ \\
\hline $\mathrm{F}$ & $15.531 * * *$ & $20.767 * * *$ & $12.533 * * *$ & $7.037 * * *$ & $02.882 * * *$ & $20.914 * * *$ \\
\hline $\mathrm{R}^{2}$ & 0.370 & 0.368 & 0.226 & 0.141 & 0.231 & 0.441 \\
\hline Adjusted $\mathrm{R}^{2}$ & 0.346 & 0.350 & 0.208 & 0.121 & 0.213 & 0.420 \\
\hline$\triangle \mathrm{R}^{2}$ & 0.336 & 0.334 & 0.198 & 0.127 & 0.217 & 0.101 \\
\hline
\end{tabular}

The function of mediating effects of SI, IS and JA can be expressed as: $a_{11} b_{1}+a_{12} b_{2}+a_{13} b_{3} ; a_{21} b_{1}+a_{22} b_{2}+a_{23} b_{3} ; a_{31} b_{1}+$ $a_{32} b_{2}+a_{33} b_{3}$. Using the bootstrapping method recommended by Preacher and Hayes [32], the author tested whether the interval of product contains 0 . The number of bootstrap samples was set to 5,000 and the confidence interval was set to $95 \%$. The results of $\mathrm{a} * \mathrm{~b}$ product coefficient and confidence interval of the mediating effects are displayed in Table 5.
As shown in Table 5, the total indirect effect of $\mathrm{CB}$ through SI, IS and JA on CP was 0.128. There is no zero in the confidence interval [0.056, 0.203], indicating the significance of the mediating effect. Concerning the individual dimensions, the mediating effect of SI was significant (0.064), that of IS was insignificant $(0.022$, with zero in the confidence interval), and that of JA was significant $(0.040$, with no zero in the confidence interval). 
Table 5. The mediating effects of SI, IS and JA

\begin{tabular}{|c|c|c|c|c|c|c|c|c|}
\hline & \multirow{3}{*}{$\begin{array}{c}\text { Point } \\
\text { estimate }\end{array}$} & \multirow{3}{*}{ SE } & \multicolumn{6}{|c|}{ Bootstrapping } \\
\hline & & & \multicolumn{2}{|c|}{ Per $95 \%$ CI } & \multicolumn{2}{|c|}{ BC 95\% CI } & \multicolumn{2}{|c|}{ BCa 95\% CI } \\
\hline & & & lower & upper & lower & upper & lower & upper \\
\hline $\mathrm{CB} \rightarrow \mathrm{CP}$ & \multicolumn{8}{|c|}{ Indirect effect } \\
\hline SI & 0.064 & 0.028 & 0.015 & 0.126 & 0.022 & 0.142 & 0.023 & 0.146 \\
\hline IS & 0.022 & 0.018 & -0.004 & 0.064 & -0.003 & 0.072 & -0.004 & 0.070 \\
\hline JA & 0.040 & 0.022 & 0.002 & 0.086 & 0.005 & 0.092 & 0.005 & 0.091 \\
\hline Total & 0.128 & 0.039 & 0.056 & 0.204 & 0.061 & 0.212 & 0.062 & 0.217 \\
\hline $\mathrm{CC} \rightarrow \mathrm{CP}$ & \multicolumn{8}{|c|}{ Indirect effect } \\
\hline SI & 0.039 & 0.022 & 0.003 & 0.093 & 0.006 & 0.099 & 0.005 & 0.097 \\
\hline IS & 0.011 & 0.015 & -0.018 & 0.043 & -0.014 & 0.050 & -0.012 & 0.052 \\
\hline JA & -0.042 & 0.021 & -0.088 & -0.003 & -0.094 & -0.008 & -0.094 & -0.008 \\
\hline Total & 0.008 & 0.032 & -0.051 & 0.075 & -0.051 & 0.075 & -0.053 & 0.073 \\
\hline $\mathrm{TR} \rightarrow \mathrm{CP}$ & \multicolumn{8}{|c|}{ Indirect effect } \\
\hline SI & 0.062 & 0.026 & 0.017 & 0.116 & 0.022 & 0.127 & 0.022 & 0.126 \\
\hline IS & 0.052 & 0.023 & 0.010 & 0.103 & 0.016 & 0.115 & 0.016 & 0.114 \\
\hline JA & 0.123 & 0.035 & 0.058 & 0.193 & 0.063 & 0.197 & 0.062 & 0.197 \\
\hline Total & 0.237 & 0.053 & 0.128 & 0.339 & 0.141 & 0.350 & 0.141 & 0.350 \\
\hline
\end{tabular}

Through the above interval tests, the total indirect effect of $\mathrm{CC}$ on $\mathrm{CP}$ was obtained as 0.008 . The mediating effects of SI and JA were 0.039 and -0.042 , respectively. However, the mediating effect of IS was not significant.

The total indirect effect of TR on CP was 0.237. The mediating effects of SI, IS and JA were $0.062,0.052$, and 0.123 respectively.

The above results show that: $\mathrm{H} 1 \mathrm{c}, \mathrm{H} 2 \mathrm{a}-2 \mathrm{~d}, \mathrm{H} 3 \mathrm{c}$, and $\mathrm{H} 4 \mathrm{a}-$ $4 \mathrm{~d}$ are not verified; $\mathrm{CC}$ has a significant negative correlation with JA, contrary to H3d; H1a, H1b, H1d, H3a, H3b, H5a-5d, and $\mathrm{H} 6-8$ are verified.

\section{CONCLUSIONS}

\subsection{Major findings}

6.1.1 The effects of influencing factors on collaboration performance

The analytical results of a Stackelberg game show that, under the cross-channel behavior, the service improvement of the retailer has a spillover effect on the direct sales channel; the cross-channel behavior promotes the retailer's service level, lower the wholesale price, and increase the profits of both channels.

Empirical results verify that the collaboration performance is greatly promoted by the cross-channel behavior (environmental adaptation level), as well as channel complementation and trust (task alignment level). However, competition pressure and manufacturer's channel power have no significant impact on collaboration performance, possibly resulted from the difference in the sensitivity to competition and the various attitudes to response to the channel power. Considering the significant positive effect of cross-channel behavior, it is concluded that the channel collaboration is mainly customer-oriented, not competition-oriented.

\subsubsection{The effects of influencing factors on channel} collaboration

Cross-channel behavior exerted a significant effect on special investment $\left(a_{11}=0.381^{*}\right)$ and joint action $\left(a_{13}=0.239^{*}\right)$, but little impact on information sharing. This means crosschannel behavior can greatly promote the investment in assets, human resources and service processes, and encourage joint action, providing value-added services to satisfy the multi- channel demand of consumers.

Trust exerted influences on special investment $\left(a_{31}=0.361^{* * *}\right)$, information sharing $\left(a_{32}=0.460 * * *\right)$ and joint action $\left(a_{33}=0.761 * * *\right)$, making it the only factor with a significant effect on information sharing. Hence, the mutual trust between the retailer and the manufacturer directly advances the channel collaboration, especially in terms of information sharing and joint action.

Channel complementation showed a positive impact on special investment SI $\left(a_{21}=0.232^{*}\right)$, an insignificant positive effect on IS $\left(a_{22}=0.091\right)$, and a significant negative effect on JA $\left(a_{23}=-0.261^{*}\right)$. This means, despite being aware of the importance of channel complementation (mean=3.723), the traditional retailer is not fully motivated to collaborate with the manufacturer, owing to the wariness of the double marginal effects.

\subsubsection{The mediating effects of channel collaboration}

Special investment and joint action both had a full positive mediating effect on the relationship between cross-channel behavior and collaboration performance $\left(\mathrm{c}_{l}{ }^{\prime}=0.099, \mathrm{P}>0.100\right)$, and showed a partial positive and negative mediating effect on the relationship between channel complementation and collaboration performance, respectively. However, information sharing had no significant mediating effect on the relationship between cross-channel behavior and channel complementation, but a full positive mediating effect on the relationship between trust and collaboration performance. Moreover, trust exhibited a significant positive effect on collaboration performance by fully mediating all three dimensions $\left(\mathrm{c}_{3}^{\prime}=0.180, \mathrm{P}>0.100\right)$. Therefore, the traditional retailer will actively share information and pursue collaboration, only if it has mutual trust with the manufacturer. In summary, special investment, information sharing and joint action are key mediators of the collaboration between the retailer and the manufacturer.

\subsection{Managerial implications}

The above findings have significant managerial implications. For the traditional retailer, it is an important development strategy to implement channel collaboration with the direct sales channel of the manufacturer. Under dynamic channel environment and task alignment, the retailer could allocate and utilize channel resources to complete the shift 
from traditional services to multi-channel services. To promote sales performance, it is crucial to understand the key role of cross-channel behavior, clarify about channel complementation, and nurture mutual trust. On the level of environmental adaptation, the retailer should carefully analyze consumer behavior, and then optimize the of channel collaboration strategy. On the level of task alignment, the retailer should leverage the complementary advantage between the two channels to achieve sustainable development in the multi-channel SC. In terms of trust, the retailer needs to communicate more with the manufacturer, and seek the supports from the latter, aiming to realize mutual interests.

For the manufacturer, the retailer and its channel are important resources in the multi-channel SC. To develop the multi-channel SC, the manufacturer should attach importance to the healthy development of the traditional sales channel, and the utilization of the direct sales channel. An important task is to guide the retailer to adapt to the consumer preferences for multi-channel services. Furthermore, the manufacturer should assist with the traditional retailer in collaboration through incentive pricing, knowledge sharing, etc., and facilitate the retailer's action of channel collaboration by signing coordination contracts.

\subsection{Contributions and future research}

This paper mainly analyzes the influencing factors of multichannel collaboration through modeling and empirical analysis. Our contributions concentrate in the following four aspects: First, 3 key factors and 3 major mediators and the associated mechanisms were addressed in the context of multichannel SC. Second, the research results on contextual ambidexterity were extended to the study of multi-channel SC, shedding new light on how to determine the factors affecting the collaboration of the traditional retailer. Third, this paper discusses the improvement of the traditional retailer's collaboration performance in an intuitive manner, and verifies the necessity and effectiveness of channel collaboration, while the previous studies were all from the perspective of the manufacturer. Fourth, the research findings provide a theoretical reference for the traditional retailer and the manufacturer in multi-channel $\mathrm{SC}$, and further enrich the empirical evidence in this area.

The future research will collect data from the other types of game players, pay attention to the collaboration of other sales channels (e.g. TV shopping and online stores), and examine the factors that have not been identified or verified.

\section{ACKNOWLEDGMENTS}

This research is supported by the National Natural Science Foundation of China [No. 71572020]; Fundamental Research Funds for the Central Universities of China [No. 2017CDJSK02PT08].

\section{REFERENCE}

[1] Zhang, J., Farris, P.W., Irvin, J.W., Kushwaha, T., Steenburgh, T.J., Weitz, B.A. (2010). Crafting integrated multichannel retailing strategies. Journal of Interactive Marketing, 24(2): https://doi.org/10.1016/j.intmar.2010.02.002
[2] Dan, B., Xu, G.Y., Liu, C. (2012). Pricing policies in a dual-channel supply chain with retail services. International Journal of Production Economics, 139(1): 312-320. https://doi.org/10.1016/j.ijpe.2012.05.014

[3] Xu, G.Y, Dan, B., Zhang, X.M., Liu, C. (2014). Coordinating a dual-channel supply chain with riskaverse under a two-way revenue sharing contract. International Journal of Production Economics, 147: 171-179. https://doi.org/10.1016/j.ijpe.2013.09.012

[4] Chiang, W.Y.K. (2010). Product availability in competitive and cooperative dual-channel distribution with stock-out based substitution. European Journal of Operational Research, 200(1): 111-126. https://doi.org/10.1016/j.ejor.2008.12.021

[5] Kollmann, T., Hasel, M. (2008). Cross-channel cooperation: on the collaborative integration of online and offline business models of e-entrepreneurs and traditional SMEs. International Journal of Entrepreneurship and Small Business, 6(2): 212-229. https://doi.org/10.1504/IJESB.2008.018629

[6] Oh, L.B., Teo, H.H., Sambamurthy, V. (2012). The effects of retail channel integration through the use of information technologies on firm performance. Journal of operations management, 30(5): 368-381. https://doi.org/10.1016/j.jom.2012.03.001

[7] Schramm-Klein, H., Wagner, G., Steinmann, S., \& Morschett, D. (2011). Cross-channel integration-is it valued by customers? The International Review of Retail, Distribution and Consumer Research, 21(5): 501-511.

[8] Gallino, S., Moreno, A. (2014). Integration of online and offline channels in retail: The impact of sharing reliable inventory availability information. Management Science, 60(6): 1434-1451. https://doi.org/10.1287/mnsc.2014.1951

[9] Wakolbinger, L.M., Stummer, C. (2013). Multi-channel management: an exploratory study of current practices. International Journal of Services, Economics and Management, 5(1-2): 112-124. https://doi.org/10.1504/IJSEM.2013.051859

[10] Berman, B., Thelen, S. (2004). A guide to developing and managing a well-integrated multi-channel retail strategy. International Journal of Retail \& Distribution Management, $\quad 32(3)$ : 147-156. https://doi.org/10.1108/09590550410524939

[11] Ramanathan, U. (2014). Performance of supply chain collaboration-A simulation study. Expert Systems with Applications, $\quad 41(1)$ : 210-220 https://doi.org/10.1016/j.eswa.2013.07.022

[12] Jap, S.D. (1999). Pie-expansion efforts: Collaboration processes in buyer-supplier relationships. Journal of Marketing Research, 36(4): 461-475. https://doi.org/10.2307/3152000

[13] Turner, N., Swart, J., Maylor, H. (2013). Mechanisms for managing ambidexterity: A review and research agenda. International Journal of Management Reviews, 15(3): 317-332. https://doi.org/10.1111/j.14682370.2012.00343.x

[14] Gibson, C.B., Birkinshaw, J. (2004). The antecedents, consequences, and mediating role of organizational ambidexterity. Academy of management Journal, 47(2): 209-226. https://doi.org/10.5465/20159573

[15] Birkinshaw, J., Gupta, K. (2013). Clarifying the distinctive contribution of ambidexterity to the field of organization studies. Academy of Management 
Perspectives,

27(4):

https://doi.org/10.5465/amp.2012.0167

$287-298$

[16] Raisch, S., Birkinshaw, J. (2008). Organizational ambidexterity: Antecedents, outcomes, and moderators. Journal of management, 34(3): 375-409. https://doi.org/10.1177/0149206308316058

[17] Jansen, J.J., Van Den Bosch, F.A., Volberda, H.W. (2006). Exploratory innovation, exploitative innovation, and performance: Effects of organizational antecedents and environmental moderators. Management science, 52(11):

$1661-1674$ https://doi.org/10.1287/mnsc. 1060.0576

[18] Kyriakopoulos, K., Moorman, C. (2004). Tradeoffs in marketing exploitation and exploration strategies: The overlooked role of market orientation. International Journal of Research in Marketing, 21(3): 219-240. https://doi.org/10.1016/j.ijresmar.2004.01.001

[19] Kollmann, T., Kuckertz, A., Kayser, I. (2012). Cannibalization or synergy? Consumers' channel selection in online-offline multichannel systems. Journal of Retailing and Consumer Services, 19(2): 186-194. https://doi.org/10.1016/j.jretconser.2011.11.008

[20] Valos, M. J., Polonsky, M., Geursen, G., Zutshi, A. (2010). Marketers' perceptions of the implementation difficulties of multichannel marketing. Journal of strategic Marketing, 18(5): 417-434. https://doi.org/10.1080/0965254X.2010.497845

[21] Chiu, H.C., Hsieh, Y.C., Roan, J., Tseng, K.J., Hsieh, J.K. (2011). The challenge for multichannel services: Crosschannel free-riding behavior. Electronic Commerce Research and Applications, 10(2): 268-277. https://doi.org/10.1016/j.elerap.2010.07.002

[22] Lavie, D. (2006). The competitive advantage of interconnected firms: An extension of the resource-based view. Academy of management review, 31(3): 638-658. https://doi.org/10.5465/amr.2006.21318922

[23] Nyaga, G.N., Whipple, J.M., Lynch, D.F. (2010). Examining supply chain relationships: do buyer and supplier perspectives on collaborative relationships differ? Journal of Operations Management, 28(2): 101114. https://doi.org/10.1016/j.jom.2009.07.005
[24] Vázquez-Casielles, R., Iglesias, V., Varela-Neira, C. (2013). Collaborative manufacturer-distributor relationships: the role of governance, information sharing and creativity. Journal of Business \& Industrial Marketing, 28(8): 620-637. https://doi.org/10.1108/JBIM-05-2011-0070

[25] Mayer, R.C., Davis, J.H., Schoorman, F.D. (1995). An integrative model of organizational trust. Academy of management review, 20(3): 709-734.

[26] van Baal, S., Dach, C. (2005). Free Riding and Customer Retention across Retailers' Channels. Journal of $\begin{array}{lll}\text { Interactive } & \text { Marketing, } & \text { 19(2): }\end{array}$ https://doi.org/10.1002/dir.20036

[27] Ramdani, B., Kawalek, P., Lorenzo, O. (2009). Predicting SMEs' adoption of enterprise systems. Journal of enterprise information management, 22(1/2): 10-24. https://doi.org/10.1108/17410390910922796

[28] Payan, J.M., McFarland, R.G. (2005). Decomposing influence strategies: argument structure and dependence as determinants of the effectiveness of influence strategies in gaining channel member compliance. Journal of Marketing, 69(3): 66-79. https://doi.org/10.1509/jmkg.69.3.66.66368

[29] Min, S., Roath, A.S., Daugherty, P.J., Genchev, S.E., Chen, H., Arndt, A.D., Glenn Richey, R. (2005). Supply chain collaboration: what's happening? The International Journal of Logistics Management, 16(2): 237-256. https://doi.org/10.1108/09574090510634539

[30] Bagozzi, R.P., Yi, Y. (1988). On the evaluation of structural equation models. Journal of the academy of marketing $\quad$ science, $16(1)$ : 74-94. https://doi.org/10.1007/BF02723327

[31] Fornell, C., Larcker, D.F. (1981). Evaluating structural equation models with unobservable variables and measurement error. Journal of Marketing Research, 18(1): 39-50. https://doi.org/10.2307/3151312

[32] Preacher, K.J., Hayes, A.F. (2008). Asymptotic and resampling strategies for assessing and comparing indirect effects in multiple mediator models. Behavior research methods, 40(3): 879-891. https://doi.org/10.3758/BRM.40.3.879 